[8] Mishra MB, Ryan $\mathrm{P}$, Atkinson $\mathrm{P}$, et al. Extra-articular features of benign joint hypermobility syndrome. Br J Rheumatol. 1996; 35(9):861-6.

Disclosure of Interests: None declared

DOI: 10.1136/annrheumdis-2019-eular.657

\section{AB0919 EFFECTS OF ALEXITHYMIA ON ACTIVITY PAIN, UPPER EXTREMITY FUNCTION, SYMPTOM AND DEPRESSION LEVELS IN PATIENTS WITH THORACIC OUTLET SYNDROME}

Yasin Tunç ${ }^{1}$, Nur Banu Karaca ${ }^{1}$, Tüzün Fırat ${ }^{1}$, Ayten Kaya Cangır ${ }^{2} .{ }^{1}$ Hacettepe University, Ankara, Turkey; ${ }^{2}$ Ankara University, Ankara, Turkey

Background: Presentation of the most common changes in the thoracic outlet syndrome causing functional disorders of the upper limb (1). The majority of the studies published on TOS highlight physiotherapy strengthening exercises and postural reducational drills as being the mainstay of any conservative management programme for TOS (2). However, in the literature, the effect of emotional state on progression in treatment programs has not been investigated. Alexithymia, which refers to deficiencies in the self-awareness of emotional states, has been reported to be associated with poor ability in various aspects of social cognition (3). The ability of TOS patients to express themselves and their emotions will affect the success of the treatment.

Objectives: The aim of this study was to investigate the effect of alexithymia on upper extremity functions, symptoms, pain level, depression and anxiety in patient with Thoracic Outlet Syndrome.

Methods: Forty-three TOS patients $(36.67 \pm 13.99$ years; 38 women, 5 men) were enrolled to the study. Alexithymia was assessed with Toronto Alexithymia Scale (TAS-20). The patients were divided into two groups as non-alexithymia group and alexithymia group according to 51 points TAS -20 cut-off score. Pain levels at rest and activity were assessed with visual analogue scale; upper extremity function was assessed with Disabilities of the Arm, Shoulder, and Hand (DASH) questionnaire, and upper extremity symptom was assessed with using Servical Brachial Symptom Questionnaire. Mann-Whitney $U$ test was used for data analyses.

Results: Activity pain level and depression in alexithymia group was higher than the non-alexithymia group, $p=0,008$ and $p=0,007$, respectively. Also, functional level and symptoms were worst in alexithymia paitents, $\mathrm{p}=0,041$ and $\mathrm{p}=0,05$, respectively. No difference was found between groups in anxiety and resting pain level $(p>0,05)$.

Conclusion: Thoracic outlet syndrome patients who have alexithymia show worse pain, symptoms, function, and depression. Emotion should be considered in physiotherapy programs. Because the progression of alexithmia patients are worst than non-alexithmia patients.

\section{REFERENCES}

[1] Laulan, J., Fouquet, B., Rodaix, C., Jauffret, P., Roquelaure, Y., \& Descatha, A. (2011). Thoracic outlet syndrome: definition, aetiological factors, diagnosis, management and occupational impact. Journal of occupational rehabilitation, 21(3), 366-373.

[2] Watson, L. A., Pizzari, T.,Balster, S. (2010). Thoracic outlet syndrome part 2: conservative management of thoracic outlet. Manual therapy, 15(4), 305-314.

[3] Moriguchi, Y., Ohnishi, T., Decety, J., Hirakata, M., Maeda, M., Matsuda, H., \& Komaki, G. (2009). The human mirror neuron system in a population with deficient self awareness: An fMRI study in alexithymia. Human brain mapping, 30(7), 2063-2076.

Disclosure of Interests: None declared

DOI: 10.1136/annrheumdis-2019-eular.7669

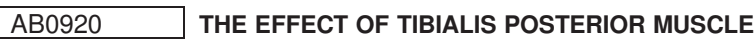 FATIQUE PROTOCOL ON THE STATIC AND DYNAMIC FOOT PARAMETERS}

Azize Reda Tunç ${ }^{1}$, Yasin Tunç ${ }^{2}$, Nilgün Bek2. ${ }^{1}$ Bilge Ozel Egitim Merkezi, Ankara, Turkey, ${ }^{2}$ Hacettepe University, Physical Therapy and Rehabilitation, Ankara, Turkey

Background: The tibialis posterior has a important key role as an invertor of the rearfoot. Also providing dynamic support across the midfoot. The value of the tibialis posterior shown by biomechanical research conducted on patients with posterior tibialis tendon dysfunction. One method of assessing a muscle's contribution to a specific movement pattern is via fatigue-inducing exercise of that muscle. Consequently, to realize the role of tibialis posterior fatigue on foot mechanics it seems prudent to use an exercise that more selectively activates this muscle $(1,2)$.

Objectives: The purpose of this study is to investigate dynamic and static foot parametres changed by tibialis posterior muscle fatique protocol.

Methods: Thirty patients were participated in this study. Socio-dermographic and descriptive characteristics of the participants were recorded The changes on the dynamic and static parametres of foot were measured by pedobarography. The two exercises selected for the fatigue protocol are: 1-Unilateral heel raise 2-Close chain resisted foot adduction Fatigue level was measured by Borg scale. Static and dynamic parameters obtained before and after fatigue protocol were compared.

Results: The mean age of the patients was $24,88 \pm 4,39$ years, mean height was $171 \pm 7,89 \mathrm{~cm}$ and mean weight was $68,7 \pm 14,5 \mathrm{~kg}$. We found significiant increase in the maximum pressure measurement of mid foot $(p=0,004)$. In the total contact area during the static position, there were no significant changes $(p>0.05)$. Participants' maximal pressure in the middle standing phase was changed from $19,78+10,71 \mathrm{~N} / \mathrm{cm}^{2}$ to $22.89 \pm 13.03 \mathrm{~N} / \mathrm{cm} 2$ after fatigue protocol in medial of middle foot $(\mathrm{p}=0.03)$.

Conclusion: According to the results, there was a correlation between the fatique of tibialis posterior and the static and dynamic parameters of foot. The increase in the middle foot peak pressure distributions after the fatigue protocol of the tibialis posterior muscle can be explained as the increase of the angular amount of pronation and prolongation of the time with the middle standing phase. Increase in pressure forces of the middle foot and increase in percentages of the area cause increase of the weight in the front foot during the gait cycle. Thus, fatigue protocol causes similar effects as tibialis posterior muscle dysfunction.

\section{REFERENCES}

[1] Bubra, P. S., Keighley, G., Rateesh, S., \& Carmody, D. (2015). Posterior tibial tendon dysfunction: an overlooked cause of foot deformity. Journal of family medicine and primary care, 4(1), 26.

[2] Pohl, M. B., Rabbito, M., \& Ferber, R. (2010). The role of tibialis posterior fatigue on foot kinematics during walking. Journal of foot and ankle research, 3(1), 6 .

Disclosure of Interests: None declared

DOI: 10.1136/annrheumdis-2019-eular.7834

\section{Paediatric rheumatology}

\section{AB0921 JUVENILE-ONSET LUPUS WITH SECONDARY CMV- INDUCED MACROPHAGE ACTIVATION SYNDROME (CASE REPORT)}

Hanan Abd EL-Lateef. Ain Shams University, Pediatric Rheumatology Immunology Unit, Cairo, Egypt

Background: Juvenile-onset lupus (JSLE) is a complex illness with an aggressive course and higher chances of morbidities and mortality. JSLE is extremely rare before the age of 5 years. A sole disease criterion may precede long time before others,making diagnosis rather challenging Objectives: Identifying JSLE and its subsequent complications

Methods: A three and half years old female patient presented with an established diagnosis of idiopathic thrombocytopenia (ITP) of one yea duration.One month ago,the patient developed an acute onset of high grade persistent fever, bilateral knee swelling and significant weight loss. Results: On physical examination, patient was emaciated and pale with multiple ecchymotic patches allover her body. Vital data showed norma blood pressure and apical heart rate ranges for age. Systemic examination revealed multiple oral ulcers, hepatosplenomegaly,bilateral knee arthritis and bilateral below knee painless pitting lower limb edema. Neurological examination was free. Laboratory evaluation showed a CBC with TLC $1.800 / \mathrm{mm}^{3}$ NE $0.5 / \mathrm{mm}^{3}$, HB $7.9 \mathrm{gm} / \mathrm{dl}$, PLT $79 \times 10^{\wedge} 3 / \mathrm{uL}$.ESR $120 \mathrm{~mm} / 1^{\text {st }} \mathrm{hr}$ and CRP $96 \mathrm{mg} / \mathrm{dl}$. Routine chemistry showed elevated liver enzymes ( ALT $137 \mathrm{IU} / \mathrm{L}$ \& AST $280 \mathrm{IU} / \mathrm{L}$ ), LDH $960 \mathrm{U} / \mathrm{L}$, serum albumin $2.5 \mathrm{~g} / \mathrm{dl}$, normal renal functions. The history of chronic ITP together with evolution of other autoimmune manifestations raised the suspicion of an underlying Connective tissue disorder. Immunological profile showed positive immune markers (ANA 1/320 speckled and positive Anti-DNA), positive lupus anticoagulant and anticardiolipin IgM,C3 was consumed(49 mg/dl). Secondary Macrophage activation syndrome (MAS) 